\title{
A Novel Route for Development of Bulk Al/SiC Metal Matrix Nanocomposites
}

\author{
Payodhar Padhi' ${ }^{1}$ and Sachikanta Kar ${ }^{2}$ \\ ${ }^{1}$ Department of Mechanical Engineering, Konark Institute of Science \& Technology, Bhubaneswar 752050, India \\ ${ }^{2}$ Department of Consultancy \& Quality, Central Tool Room \& Training Center, Bhubaneswar 752024, India
}

Correspondence should be addressed to Payodhar Padhi, payodharpadhi@gmail.com

Received 15 March 2011; Revised 5 May 2011; Accepted 6 May 2011

Academic Editor: Baoquan Sun

Copyright ( $) 2011$ P. Padhi and S. Kar. This is an open access article distributed under the Creative Commons Attribution License, which permits unrestricted use, distribution, and reproduction in any medium, provided the original work is properly cited.

\begin{abstract}
Addition of nano particles, even in quantities as small as 2 weight percent can enhance the hardness or yield strength by a factor as high as 2 . There are several methods for the production of metal matrix nanocomposites including mechanical alloying, vertex process, and spray deposition and so forth. However, the above processes are expensive. Solidification processing is a relatively cheaper route. During solidification processing, nano particulates tend to agglomerate as a result of van der Waals forces and thus proper dispersion of the nano particulate in metal matrix is a challenge. In the present study a noncontact method, where the ultrasonic probe is not in direct contact with the liquid metal, was attempted to disperse nanosized SiC particulates in aluminum matrix. In this method, the mold was subjected to ultrasonic vibration. Hardness measurements and microstructural studies using HRTEM were carried out on samples taken from different locations of the nanocomposite ingot cast by this method.
\end{abstract}

\section{Introduction}

The mechanical properties of nanoparticle dispersion strengthened MMCs are far superior to those of micrometric dispersion strengthened MMCs with a similar volume composition of particulate. For example, the tensile strength of an $\mathrm{Al}-1 \mathrm{vol} . \% \mathrm{Si}_{3} \mathrm{~N}_{4}(10 \mathrm{~nm})$ composite has been found to be comparable to that of an Al-15 vol.\% SiCp $(3.5 \mu \mathrm{m})$ composite, the yield stress of the nanometric MMC being significantly higher than that of the micrometric MMC [17]. Particles larger than $1.5 \mu \mathrm{m}$ tend to act as microconcentrators and are susceptible to cleavage [1]. On the other hand, particles in the range of 200-1500 $\mathrm{nm}$ have been found to cause the formation of cavities and pits caused by poor interphase cohesion [1]. Particles smaller than $200 \mathrm{~nm}$ generally bond well with the matrix, which is key to the excellent mechanical properties of nanoscale particulate MMCs [1].

There are several methods for the production of metal matrix nanocomposites including mechanical alloying, vertex process, and spray deposition $[8,9]$. But the above processes are expensive. Solidification processing is a relatively cheaper route. However, when the nanoparticles are mixed with liquid metal during the casting, they agglomerate due to interparticle van der Waals force. Dispersion of the nanoparticles in the liquid media will require large amount of force to break the bonds in between the particles. The mechanical means used in the conventional methods to cast MMCs will not be sufficient to deagglomerate the nanoparticles. Also, when the nanopowder is added into the melt the viscosity of the melt increases significantly. This hinders the mixing process. The lower the particle size is the higher will be the viscosity of the melt [10], and the higher is the volume fraction of particulate, the higher will be the viscosity [10]. Therefore, it is very difficult to uniformly disperse nanoparticles in metal matrix.

Yang et al. [8] overcame the problem of agglomeration by using ultrasonic waves. The ultrasonic wave generates nonlinear effects in the liquid-like transient acoustic cavitation and acoustic streaming, which are responsible for refining microstructures, degassing of liquid metal, and dispersing the nanoparticles [8]. Acoustic cavitation refers to the formation, growth, and implosive collapse of bubbles in the liquid. Cavitation collapse can locally raise the temperature to as high as $\sim 20000 \mathrm{~K}$ [11]. It raises the pressure adjacent to the collapse to as high as $1000 \mathrm{~atm}$. The heating and cooling rate of $\sim 10^{9} \mathrm{~K} / \mathrm{s}$ and liquid jet streams of $\sim 400 \mathrm{~km} / \mathrm{h}$ have been reported during the cavitation [12-15]. 


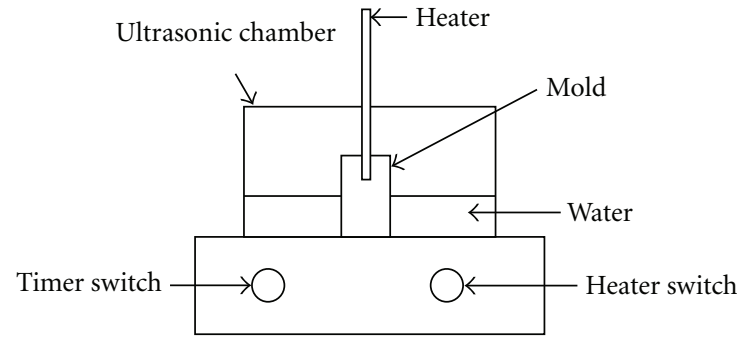

FIgURE 1: Schematic diagram for experimental setup.

TABle 1: Compositions commercially pure Aluminium.

\begin{tabular}{lcccc}
\hline Element & $\mathrm{Fe}$ & $\mathrm{Mg}$ & $\mathrm{Si}$ & $\mathrm{Al}$ \\
\hline $\mathrm{Wt} \%$ & 0.96 & 0.43 & 0.26 & Balance \\
\hline
\end{tabular}

When sound wave propagates through the liquid, alternating high-pressure (compression) and low-pressure (rarefaction) cycles are generated. During the low-pressure cycle, small bubbles or voids are nucleated. After the bubbles reach the critical size, they collapse violently during the high-pressure cycle. During the collapse of bubbles, high-pressure shock waves are generated. They propagate through the liquid at velocities above the speed of sound and break up the agglomerations, thus breaking the interparticle van der Waals forces [8]. Eskin et el. [14] fabricated both Al-SiC and $\mathrm{Mg}-\mathrm{SiC}$ nanocomposites using ultrasonic wave of $20 \mathrm{kHz}$ frequency and $600 \mathrm{~W}$ power. In the method adopted by Yang et al. the source of the ultrasonic wave or the probe was dipped into the liquid metal $[2,10]$.

However, the above technique has several drawbacks such as the oscillating probe may dissolve in liquid metal thus contaminating the liquid [16]. Moreover, the intensity of cavitation is not uniform. It is maximum near the probe, and it gradually decreases as one moves away from the probe. Further, the direct contact of probe with liquid metal is not possible for continuous casting.

To overcome the above difficulties, a noncontact method was attempted to mix up nanosized particulates in aluminum matrix. A simple setup was made to carry out the preliminary study for nanoparticle distribution by the noncontact method. In this method, the mold is subjected to ultrasonic vibration. A simple setup was made to cast MMNCs weighing up to $305 \mathrm{gm}$. The method was successful in uniformly dispersing the nanosized particulates of $\mathrm{SiC}$ in Al matrix.

\section{Noncontact Ultrasonic Method of Casting Metal Matrix Nanocomposites}

The experimental setup is shown in Figure 1. The setup consists of an ultrasonic generator which generates ultrasonic

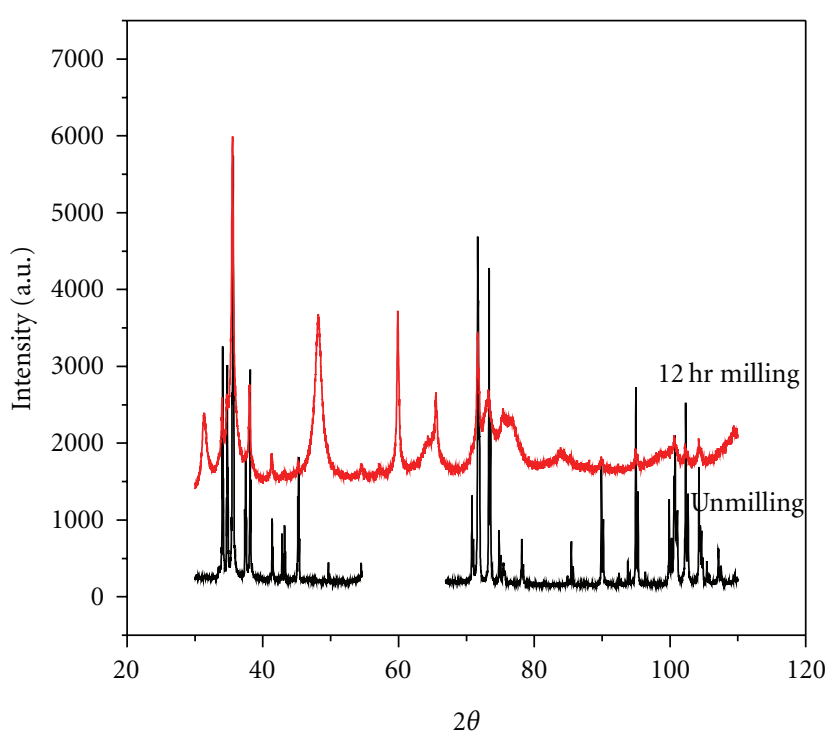

Figure 2: X-ray diffraction of both milled ( $12 \mathrm{hrs)}$ and unmilled SiC powders.

waves at a frequency of $35 \mathrm{kHz}$ (Bandelin-Germany MakeModel: RK-100H), an ultrasonic chamber, steel die, and hanging heating filament. Sufficient water was kept around the die for effective transmission of ultrasonic waves from the sides of the chamber. Mold was preheated to avoid thermal cracking. The preheated mold was kept in the ultrasonic chamber, and the chamber was subjected to vibration at a frequency of $35 \mathrm{kHz}$. Liquid aluminum and $\mathrm{SiC}$ particulate $(2-3 \mathrm{wt} \%)$ having average size of $12.3 \mathrm{~nm}$ were simultaneously poured into the vibrating mold. After the simultaneous pouring, the heating element was immediately brought down above the liquid metal in order to delay the solidification. The vibration was carried out for a period of five minute to ensure complete mixing. The castings were cut in both longitudinal and transverse section and polished for microstructural evaluation.

\subsection{Starting Material}

2.1.1. Commercially Pure Aluminum. The composition of commercially pure aluminum used for casting $\mathrm{Al}$ matrix nanocomposites is shown is Table 1 .

2.1.2. Ceramic Particulate. SiC nanoparticles were used as reinforcements. These were prepared by ball milling. SiC powder was milled for 12 hours. The nanopowders were characterized using high-resolution X-ray diffractometer (PHILLIPS, X-PERT-PRO) and high-resolution transmission electron microscope (JEOL, JEM-2100). Figure 2 shows the X-Ray diffractograms of milled and unmilled SiC powders. Based on Scherrer's equation, the X-ray diffractograms were analysed for estimating the crystallite size of SiC. Using this method, the estimated crystallite size for $\mathrm{SiC}$ was $12.3 \mathrm{~nm}$. Figure 3 shows the HRTEM photograph of SiC. It can be seen from Figure 3 that the particle size of $\mathrm{SiC}$ varied from $\sim 10 \mathrm{~nm}$ to $\sim 20 \mathrm{~nm}$. 


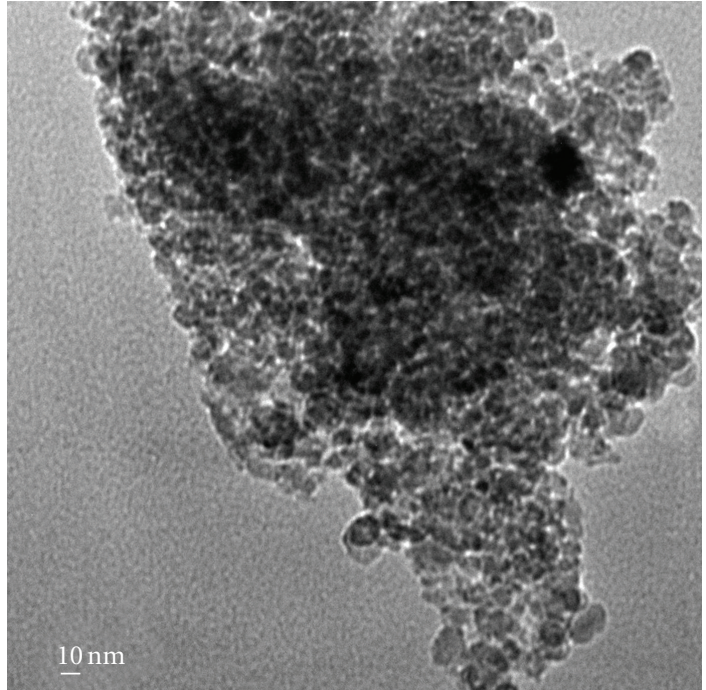

Figure 3: HRTEM photograph of SiC Powders.

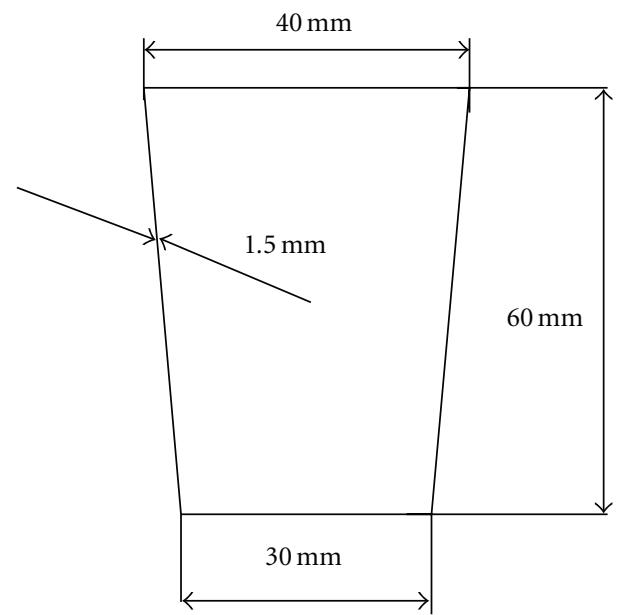

FIgURE 4: Schematic diagram of stainless steel mold.

2.1.3. Experimental Setup. The descriptions of the ultrasonic vibrator, mold, and the heating system are as follows.

(a) Ultrasonic vibrator: Ultrasonic Bath (Bandelin-Germany Make-Model: RK-100H) was used to generate the ultrasonic wave of $35 \mathrm{kHz}$ frequency. At the base of the chamber was a mesh on which the mold was fixed. The mold was surrounded by sufficient water so that effective transmission of ultrasonic waves to liquid metal could take place. The time period of vibration could be varied from 1 minute to 30 minute.

(b) Mold: the mold was made of stainless steel and its geometry is shown in Figure 4.

(c) Heating system: Figures 5 and 6 show the heating system. It consisted of a ceramic cylinder with a central hole surrounded by another six holes, all parallel to the axis of the cylinder. Through these holes, heating coil $(1000 \mathrm{~W})$ was passed. The heating system was lowered and lifted using a pulley system.

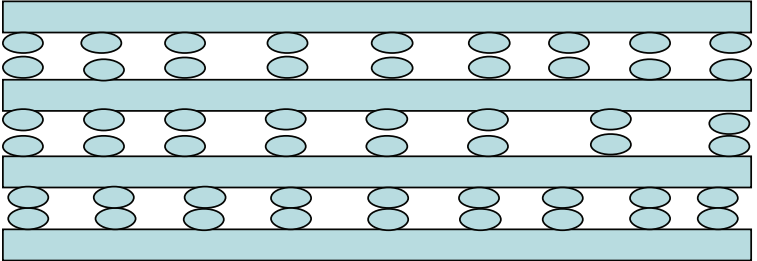

FIGURE 5: Schematic diagram of heater.

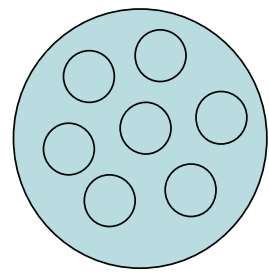

FIgure 6: Cross sectional view of heater.

\section{Procedure for Characterization of Cast Ingot}

3.1. Specimen Preparation for Microstructural Study. The specimens were cut with low-speed abrasive cutter for microstructural analysis. Three different grades (60, 400, and 600 grits) of emery papers were used to polish the specimen surface. Then, using alumina fine powder cloth polishing for about 20 minute was carried out. The surface was cleaned with alcohol solution. Finally, diamond polishing was done and the specimen surface was cleaned with acetone. The specimens were etched with Keller's reagent. The etching was done for 30 seconds. Etched specimens were cleaned in acetone using an ultrasonic vibrator and dry hot air. The specimens were cold mounted in order to achieve a uniform flatness of specimen surface and the cold mount base.

3.2. Preparation of Specimens for TEM Study. Thin slice of specimen was cut out using low-speed diamond cutter. The first stage of thinning was done by placing the specimen over a belt grinder. The slice was then attached to a block using suitable adhesive and subjected to thinning using emery paper (6 grit). The thickness of the specimen was reduced below $100 \mu \mathrm{m}$. Finally, discs of $3 \mathrm{~mm}$ diameter were punched out of the specimen using mechanical punch (Gaton Model 642). Then, prethinning of the discs was carried out using a dimple grinder (Gaton Model-656). By dimpling, the centre regions of the discs were thinned to $\sim 20 \mu \mathrm{m}$ from a thickness of $\sim 100 \mu \mathrm{m}$. The prethinned discs were finally subjected to ion milling (Gaton Precision Polishing System Model 691). The difference between the top and bottom gun angles of the ion milling machine was $3.5^{\circ}$. The vacuum inside the ion beam milling chamber was $10^{-6}$ Torr. A beam of $5 \mathrm{KeV}$ was used for ion milling. As a result of ion milling, a hole was formed in the centre and the region around the hole was thin enough to be examined under a TEM.

3.3. TEM Characterization. For TEM analysis, Highresolution TEM (JEOL, JEM-2100) was used. The TEM 


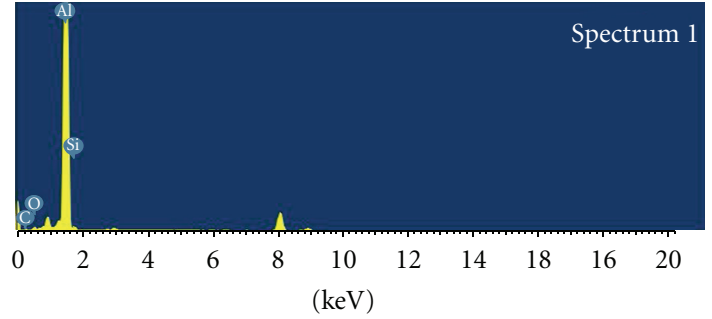

Full-scale 15269 cts Cursor: $0 \mathrm{keV}$

FIgURE 7: EDAS of Al-SiC nanocomposites.

operated at an accelerating voltage of $200 \mathrm{kV}$. Bright field images of nanoparticulates spread in the Al matrix were taken and selected area diffraction patterns were recorded. EDAX was also carried out.

\section{Results of Characterization of Cast Metal Matrix Nanocomposites}

4.1. Commercially Pure Al. Commercially pure Al was cast by the noncontact ultrasonic method, without addition of any particulate. The microhardness was $\sim 51 \mathrm{Hv}$, which is much higher than the commercially pure $\mathrm{Al}$ used in the present study.

4.2. SiC Nanocomposite. MMNCs with two different volume fractions of SiC namely. 0.0263 and 0.016 , were cast. The total weight of the ingot having 2.63 volume percentage ( $3 \mathrm{wt} \%$ ) of $\mathrm{SiC}$ was $310 \mathrm{gm}$ and that of the ingot having 1.6 volume percentage $(2 \mathrm{wt} \%)$ of $\mathrm{SiC}$ was $205 \mathrm{gm}$. The cast ingots were longitudinally cut for the hardness and microstructural characterization of the ingot.

4.3. Results of TEM Studies. Figure 7 shows EDAS of Al$\mathrm{SiC}$ nanocomposites confirming the $\mathrm{SiC}$ nanoparticles in the composites. TEM samples were made from different regions of the cast. From the qualitative observation, it can be inferred that the $\mathrm{SiC}$ nanoparticles have got dispersed uniformly within the ingot. However within a length scale of $1 \mu \mathrm{m}$, one can observe segregation of the nanoparticles. It is possible that the nanoparticles have segregated in the grain boundary region. Figure 8 shows the TEM micrographs of $\mathrm{Al}-2 \mathrm{wt} \% \mathrm{SiC}$ nanocomposite taken at different magnifications. Figure 8(a) shows the SiC nanoparticles spread uniformly. They are possibly surrounded by subgrains. Figure 8(b) shows the $\mathrm{SiC}$ nanoparticles segregated along a line, which is possibly a grain boundary.

\section{Discussions}

5.1. Distribution of Nanoparticles in Al matrix. From the microhardness values taken from different locations of the ingot, it is clear that the distribution of nanoparticles is uniform across the ingot. It appears that, in the liquidmetal nanoparticles were uniformly dispersed and the segregation of the particles near the grain boundaries is due to pushing

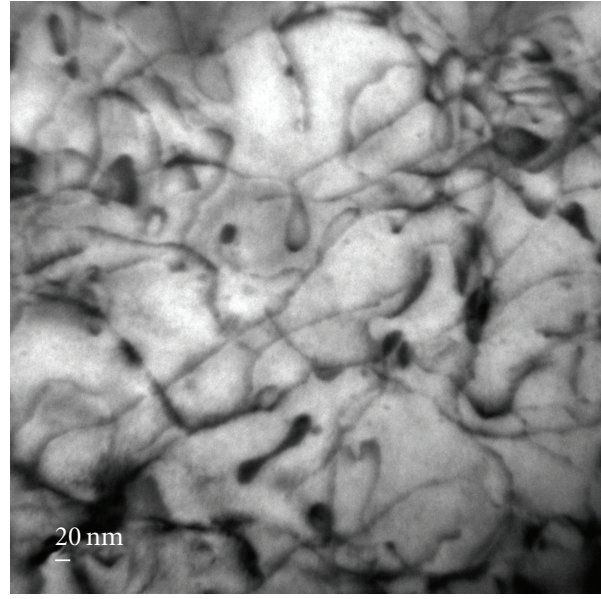

(a)

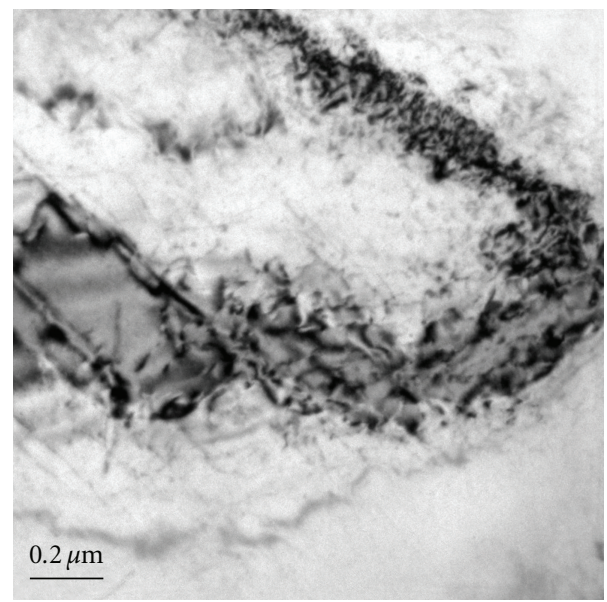

(b)

Figure 8: TEM micrographs of Al-SiC nanocomposites.

of the nanoparticles during the growth of the grains. As the grains grew, the nanoparticles were pushed into the remaining liquid regions. In majority of metal-ceramic combinations [17] gives the critical velocity for engulfment of particulate in solidified metal:

$$
V_{c r}=\frac{0.157}{\eta} \Delta \sigma^{2 / 3} \sigma_{s l}\left(\frac{a}{R}\right)^{4 / 3},
$$

where $V_{c r}$ is the critical solidification front velocity, $\Delta \sigma=$ $2 \sigma_{c s}-\sigma_{c l}-\sigma_{s l}, \sigma_{i j}$ being the interfacial energy between phases $i$ and $j$ ( $l=$ liquid, $g=$ gas, $c=$ ceramic, and $s=$ solidified metal), $\eta$ is the dynamic viscosity of liquid metal, $a$ is the diameter of the atom in liquid metal, and $R$ is the particle radius.

As evident from the equation, the critical velocity required for engulfment of nanoparticles will be very high and thus a large fraction of nanoparticles will be pushed near the grain boundaries. The mechanism of uniform distribution of nanoparticle within liquid metal subjected to ultrasonic vibration is well understood. Nanoparticles have a tendency to agglomerate due to van der Waals forces. Thus, during 
casting of nanocomposites, high-intensity ultrasound has been used for mixing, dispersing, and deagglomeration the nanoparticles [10]. When sound wave propagates into the liquid, alternating high-pressure (compression) and lowpressure (rarefaction) cycles are generated. During the lowpressure cycle, small bubbles or voids get nucleated in the liquid. When the bubble reaches a critical size at which it can no longer absorb energy, they collapse violently during the high-pressure cycle. The process of bubble formation and collapse is called cavitation. During the collapse of bubbles, high-pressure shock waves are generated and propagate through the liquid at velocities above the speed of sound, which keep the nanoparticles uniformly dispersed.

\section{Conclusions}

(1) In certain locations, we achieved uniform distributions of $\mathrm{SiC}$ nanoparticles in the aluminium matrix.

(2) TEM studies reveal segregation of particles near the grain boundaries suggesting pushing of nanoparticles during grain growth.

(3) More number of experiments are required to find out the degree of uniform distributions of nano particles.

\section{References}

[1] Y. C. Kang and S. L. Chan, Materials Chemistry and Physics, vol. 65 , p. 436, 2004.

[2] J. Hashim, L. Looney, and M. S. J. Hashmi, "Metal matrix composites: production by the stir casting method," Journal of Materials Processing Technology, vol. 92-93, pp. 1-7, 1999.

[3] J. Hashim, L. Looney, and M. S. J. Hashmi, "Particle distribution in cast metal matrix composites-part I," Journal of Materials Processing Technology, vol. 123, no. 2, pp. 251-257, 2002.

[4] J. Hashim, L. Looney, and M. S. J. Hashmi, "Particle distribution in cast metal matrix composites-part II," Journal of Materials Processing Technology, vol. 123, no. 2, pp. 258-263, 2002.

[5] A. Ourdjini, K. C. Chew, and B. T. Khoo, "Settling of silicon carbide particles in cast metal matrix composites," Journal of Materials Processing Technology, vol. 116, no. 1, pp. 72-76, 2001.

[6] A. Kolsgaard and S. Brusethaug, "Settling of SiC particles in an AlSi7Mg melt," Materials Science and Engineering A, vol. 173, no. 1-2, pp. 213-219, 1993.

[7] S. Charles and V. P. Arunachalam, "Effect of particle inclusions on the mechanical properties of composites fabricated by liquid metallurgy," Indian Journal of Engineering and Materials Sciences, vol. 10, no. 4, pp. 301-305, 2003.

[8] Y. Yang, J. Lan, and X. Li, "Study on bulk aluminum matrix nano-composite fabricated by ultrasonic dispersion of nanosized $\mathrm{SiC}$ particles in molten aluminum alloy," Materials Science and Engineering A, vol. 386, no. 1-2, pp. 284-290, 2004.

[9] B. S. Murty and K. Hono, "Al- Mg- and Fe-based nanocomposites by rapid solidification processing," Transactions of the Indian Institute of Metals, vol. 58, no. 4, pp. 769-775, 2005.

[10] T. Hielscher, "Ultrasonic production of nano-size dispersions and emulsions," in Proceedings of European Nanosystems Conference (ENS '05), Paris, France, December 2005.
[11] D. J. Flannigan and K. S. Suslick, "Plasma formation and temperature measurement during single-bubble cavitation," Nature, vol. 434, no. 7029, pp. 52-55, 2005.

[12] K. S. Suslick, Ultrasound: Its Chemical, Physical, and Biological Effects, VCH, New York, NY, USA, 1988.

[13] G. I. Eskin, "Broad prospects for commercial application of the ultrasonic (cavitation) melt treatment of light alloys," Ultrasonics Sonochemistry, vol. 8, no. 3, pp. 319-325, 2001.

[14] G. I. Eskin, "Cavitation mechanism of ultrasonic melt degassing," Ultrasonics Sonochemistry, vol. 2, no. 2, pp. S137S141, 2001.

[15] G. I. Eskin and D. G. Eskin, "Production of natural and synthesized aluminum-based composite materials with the aid of ultrasonic (cavitation) treatment of the melt," Ultrasonics Sonochemistry, vol. 10, no. 4-5, pp. 297-301, 2003.

[16] C. Vivés, "Progress in fluid flow research: turbulence and applied MHD," in Effects of Oscillatory Electromagnetic Force Fields on Microstructure of Solidifying Aluminum Alloys, vol. 162, chapter 40, pp. 601-617, AIAA, 1998.

[17] G. Kaptay, "Interfacial criteria for producing metal matrix composites and ceramic particle stabilized metallic foams," Materials Science Forum, vol. 414-415, pp. 419-424, 2003. 

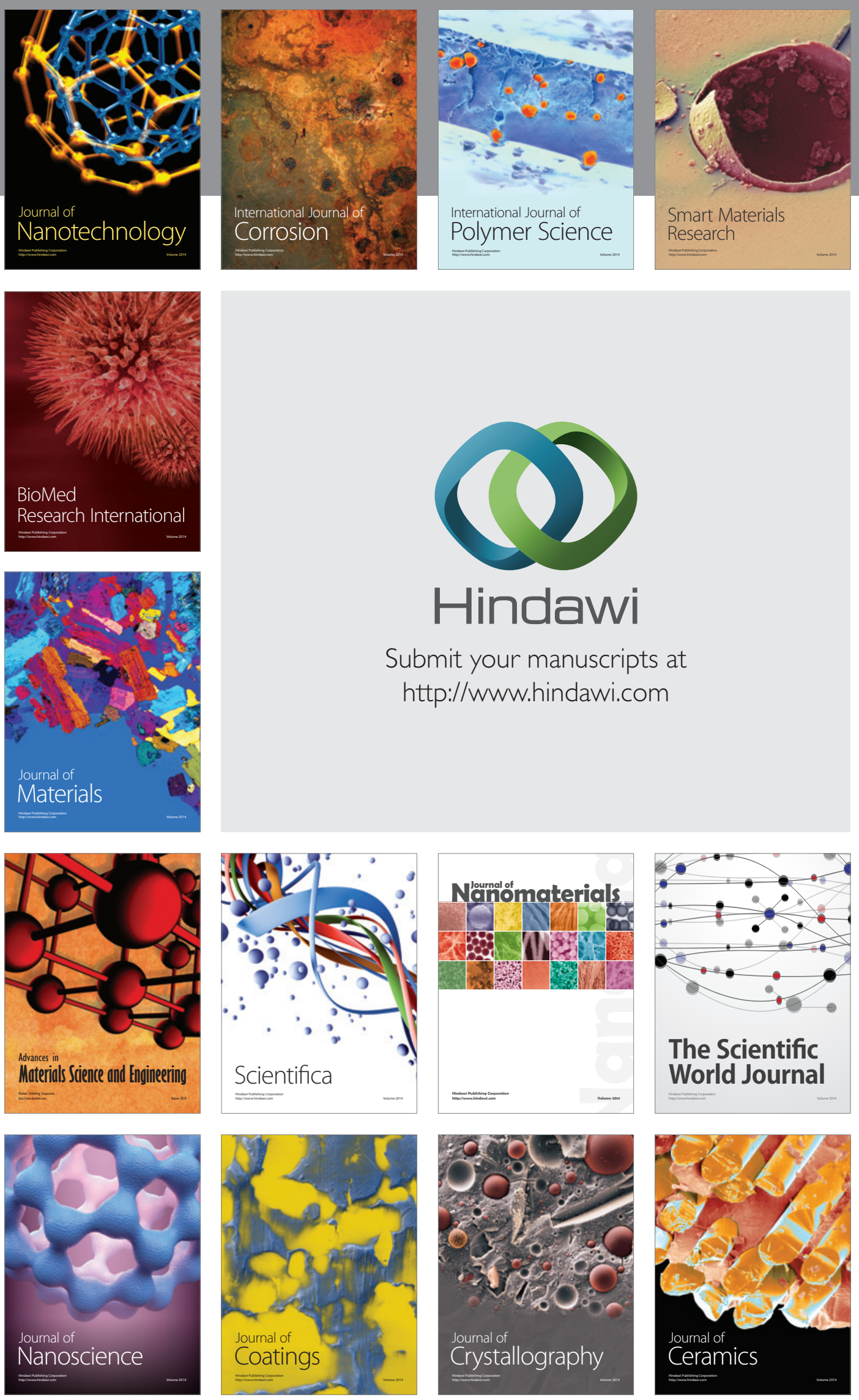

The Scientific World Journal

Submit your manuscripts at

http://www.hindawi.com

\section{World Journal}

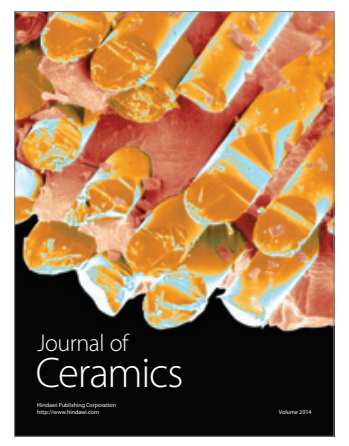

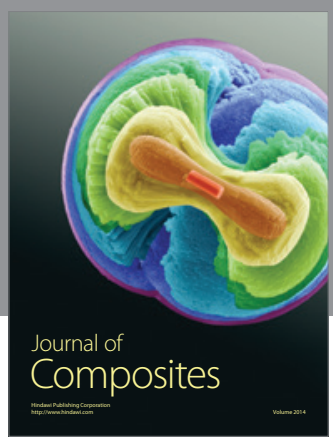
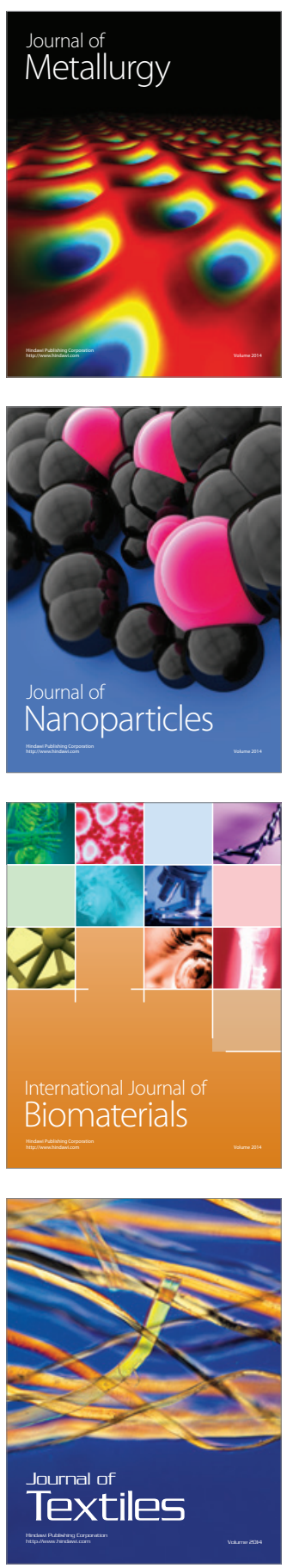